\title{
Importância da Metodologia na Dosagem de Testosterona Sérica: Comparação entre um Imunoensaio Direto e um Método Fundamentado em Cromatografia Líquida de Alta Performance e Espectrometria de Massa em Tandem (HPLC/MS-MS)
}

perspectiva

\author{
José GILBERTO H. VieiRa \\ ODETE H. NAKAMURA \\ CláUdia MARIA FerRer \\ TERESINHA T. TACHIBANA \\ Maria Helena K. Endo \\ VALDEMIR M. CarValHo
}

Setores de Imunologia (JGHV, CMF, TT, MHKE) e Cromatografia $(\mathrm{OHN}, \mathrm{VMC})$ de Fleury Medicina e Saúde, São Paulo, SP, Brasil.

Recebido em 31/1/2008 Aceito em 4/6/2008

\author{
RESUMO
}

A dosagem de testosterona sérica, total ou fração livre, é metodologia de alto valor diagnóstico e encontra-se disponível na maioria dos laboratórios clínicos. Esta disponibilidade foi possível pelo desenvolvimento de metodologias simples e diretas, adaptáveis a plataformas de dosagem automatizada. Uma série de publicações recentes tem alertado quanto às limitações destas metodologias, em especial em amostras com baixas concentrações, como muIheres e crianças. Neste trabalho serão apresentados os resultados do emprego de uma metodologia de referência, fundamentada em cromatografia líquida de alta performance e espectrometria de massa em tandem (HPLC/ MS-MS), e sua comparação com uma dosagem de rotina (ensaio eletroquimioluminescente - ECLIA). Os métodos são comparados tanto na dosagem de testosterona total $(n=213)$ quanto na determinação de testosterona livre calculada com base na determinação da testosterona total e da proteína carregadora de hormônios sexuais (SHBG) $(n=135)$. Os valores obtidos com o ECLIA são significativamente mais elevados, sendo a dispersão mais nítida em soros com baixas concentrações. Tal fenômeno fica mais claro quando apresentado na forma de gráficos de Bland-Altman. Neste trabalho são discutidas as dificuldades de implementação de uma metodologia de referência, como a apresentada, e a convivência com as metodologias de rotina, bem como a literatura recente sobre o assunto. (Arq Bras Endocrinol Metab 2008; 52/6:1050-1055)

Descritores: Testosterona sérica total; Testosterona sérica livre; Imunoensaio; Cromatografia líquida de alta performance; Espectrometria de massa; Gráfico de Bland-Altman

\section{ABSTRACT}

The Importance of Methodology in Serum Testosterone Measurement: Comparison Between a Direct Immunoassay and a Method Based on High Performance Liquid Chromatography and Tandem Mass Spectrometry (HPLC/ MS-MS).

Serum testosterone in its total or free form, is a highly valuable diagnostic test and is available in the great majority of clinical laboratories. This reality was possible due to the development of simple and direct assays, adaptable to large automatic systems. Recent publications have called attention to the limitations of these simplified methodologies, mainly in samples with low concentration, as women and children. In this paper we present results obtained using a reference method based on high performance liquid chromatography and tandem mass spectrometry (HPLC/MS-MS) and its comparison with those obtained with a commercial routine immunoassay (electrochemiluminescent assay, ECLIA). Methods were compared in total testosterone measurement $(n=213)$, as well as in free testosterone evaluation based on calculation including sex hormone-binding protein (SHBG) levels $(n=135)$. Values obtained with ECLIA were significantly higher, with more marked dispersion in low con- 
centration. This phenomenon is clearer when presented as a Bland-Altman plot. Difficulties in the implementation of reference methods as the one presented are discussed, as well as the necessity of caution in the interpretation of values obtained with routine assays, a matter of several publications in recent literature. (Arq Bras Endocrinol Metab 2008; 52/6:1050-1055)

Keywords: Serum total testosterone; Free serum testosterone; Immunoassay; High performance liquid chromatography; Mass spectrometry; BlandAltman plot.

\section{INTRODUÇÃO}

$\mathrm{A}^{\mathrm{n}}$ DOSAGEM DE TESTOSTERONA sérica faz parte da rotina laboratorial há mais de duas décadas, com indicações e utilidades bem definidas. Desde a introdução do primeiro radioimunoensaio (RIE), no início da década de 1970 (1), o que tornou a dosagem viável tecnicamente, as metodologias para sua medida passaram por várias transformações. Os primeiros ensaios viáveis, como o descrito por Furuyama, Mayes e Nugent (1), incluíam extração do soro seguida de cromatografia como método preparativo pré-RIE. Já o RIE, propriamente dito, incluía incubação de várias horas, uso de material radioativo (testosterona triciada) e separação de fases, com o emprego de solução de carvão ativado. A complexidade do processo pré-analítico e a necessidade de equipamentos especiais limitaram a dosagem a laboratórios de pesquisa ou de referência. A constatação, decorrente do acúmulo de experiência, de que a dosagem de testosterona sérica apresentava grande utilidade clínica, forçou maior disseminação da metodologia e levou a tentativas de aprimoramento e, principalmente, simplificação do ensaio.

A produção de anticorpos de maior afinidade e especificidade, poli ou monoclonais, foi um dos passos seguidos, proporcionando metodologias mais simples, dispensando o processo cromatográfico, sem aparente perda da acurácia da medida (2). A adaptação da metodologia para as plataformas de automatização existentes nos grandes laboratórios comerciais, bem como sua disponibilidade como metodologia simplificada para laboratórios clínicos de rotina, exigiu simplificações ainda maiores. Estas incluíram a utilização de traçadores não radioativos e eliminação dos processos de preparação pré-analíticos pelo emprego de inibidores da ligação da testosterona com a globulina ligadora de hormônios sexuais (sex hormone-binding globulin [SHBG]) (3). A dosagem de testosterona sérica tornou-se rotina diagnóstica plenamente disponível sem necessidade de extração e cromatografia e utilizando plataformas automatizadas disponíveis na maioria dos laboratórios clínicos.

O uso generalizado dessas novas metodologias trouxe vantagens em termos de disponibilidade e custos, mas ao mesmo tempo suas limitações tornaram-se manifestas e várias publicações começaram a chamar a atenção para a falta de acurácia, em especial em baixas concentrações (mulheres e crianças) $(4,5)$. As evidências são tão fortes que estimularam a Sociedade Americana de Endocrinologia (Endocrine Society) a preparar e publicar recentemente posicionamento oficial alertando para os cuidados na interpretação das dosagens de rotina de testosterona e clamando pelo desenvolvimento de novas metodologias mais acuradas (6).

Se no caso da dosagem de testosterona total as limitações dos métodos simplificados tornaram-se evidentes, no caso da determinação de sua fração livre os fatos são ainda mais marcantes. Como a testosterona encontrada no soro apresenta-se basicamente ligada a proteínas, sendo a fração livre (biologicamente ativa) da ordem de apenas $1 \%$ a $3 \%$, a dosagem total se sujeita a flutuações induzidas pelas variações quantitativas das proteínas carregadoras, em especial a SHBG. A medida da fração livre seria o ideal, mas os métodos de referência incluem diálise prévia e ensaios de alta sensibilidade (7). Adaptações, visando a simplificação, foram desenvolvidas, mas as restrições descritas quanto à dosagem de testosterona total aplicam-se também às da fração livre, sendo os métodos diretos sem diálise considerados inaceitáveis (8). Os métodos indiretos, com base na dosagem de testosterona total e de SHBG, e aplicação de cálculos para a avaliação da fração livre apresentam boa correlação com o método de referência (9), mas continuam na dependência da acurácia da dosagem de testosterona total, o que remete aos problemas descritos anteriormente.

Qual é a solução? Evidentemente, o ideal seria a aplicação geral de técnicas de alta sensibilidade, especificidade e acurácia, como as que utilizam os princípios 
de cromatografia líquida de alta performance como método preparativo e espectrometria de massa em tandem para quantificação (HPLC/MS-MS). Estas metodologias, descritas nos últimos anos e comparadas com os métodos fundamentados em RIE, têm demonstrado alta especificidade e acurácia, sendo consideradas como métodos de referência para as dosagens de esteróides em fluidos biológicos (10). No caso da testosterona, várias publicações fundamentadas em HPLC/MS-MS foram recentemente apresentadas e demonstraram sua superioridade em relação aos métodos tradicionais, especialmente em amostras de mulheres e crianças (11-13). Dois problemas básicos ainda limitam sua aplicação em rotina diagnóstica: o alto custo dos equipamentos necessários e a expertise superior necessária para sua realização.

Neste trabalho, foram apresentados os resultados obtidos com a utilização de um método de referência (HPLC/MS-MS) e a comparação com os resultados obtidos com um método direto de rotina em plataforma automatizada. Foram comparados os resultados da medida de testosterona total, bem como da livre calculada, e discutida a literatura recente sobre o tema e suas implicações práticas.

\section{MÉTODOS}

\section{Amostras}

Para a comparação das dosagens de testosterona total foram empregadas 214 amostras de nossa rotina diagnóstica, tornadas anônimas, provenientes de 40 pacientes do sexo masculino e 174 do sexo feminino, com idades entre 6 e 76 anos, com média de 38 anos. Para a comparação entre as determinações de testosterona livre calculada com base nos dois ensaios de testosterona, foram empregadas 135 amostras, sendo 20 do sexo masculino e 115 do feminino, com idades entre 9 e 71 anos, com média de 37 anos.

\section{Dosagens de testosterona}

\section{HPLC/MS-MS}

O padrão de testosterona (Steraloids, New Port, RI, EUA) foi preparado em soro livre de esteróides obtido por tratamento com carvão ativado e ultracentrifugação. As concentrações foram $25,100,250,500 \mathrm{e}$ $1.000 \mathrm{ng} / \mathrm{dL}$ (respectivamente, 0,$87 ; 3,47 ; 8,7 ; 17,4$ e $34,7 \mathrm{nmol} / \mathrm{L})$. O padrão interno utilizado foi tes- tosterona-d2 (C/D/N Isotopes, Quebec, Canadá) na concentração de $50 \mathrm{ng} / \mathrm{dL}(1,74 \mathrm{nmol} / \mathrm{L})$ em água ultrapura. Como precipitante foi usado sulfato de zinco $0,2 \mathrm{M}$ em metanol $80 \%$. A $300 \mathrm{\mu L}$ de soro, padrão ou controle, foram adicionados $20 \mu \mathrm{L}$ de solução de padrão interno e $300 \mu \mathrm{L}$ da solução precipitante. Após agitação por um minuto, a amostra foi centrifugada por dez minutos a $13.000 \mathrm{rpm}$ e o sobrenadante transferido para poços de placa deepwell $(96 \times 1 \mathrm{~mL})$, de onde $400 \mu \mathrm{L}$ foram transferidos para o aparelho de HPLC Waters $1525 \mu$, em que a extração on-line foi feita empregando-se coluna monolítica Cl8 $5 \times 4,6 \mathrm{~mm}$ com eluente acetronitrila a $5 \%$ e fluxo de $5 \mathrm{~mL} / \mathrm{min}$. A cromatografia é seqüencial e realizada em coluna monolítica C18 $25 \times 4,6 \mathrm{~mm}$, mantida a $50{ }^{\circ} \mathrm{C}$, utilizando sistema isocrático com eluente de $55 \%$ metanol em formiato de amônio $0,5 \mathrm{mM}$ e fluxo de $1,5 \mathrm{~mL} / \mathrm{min}$. A fração do eluato, correspondente à testosterona, é injetada em espectrômetro de massas utilizando a técnica de ionização a pressão atmosférica (APCI) em modo positivo e as massas monitoradas são: testosterona 289,2 > 109,1 (qualificador) > 97,1 (quantificador) e testosterona d2 291,2 > 111.1 (qualificador) > 99,1 (quantificador). A sensibilidade do ensaio é da ordem de $7 \mathrm{ng} / \mathrm{dL}(0,24 \mathrm{nmol} / \mathrm{L})$. O coeficiente de variação intra-ensaio estudado em uma amostra com valor médio de $159 \mathrm{ng} / \mathrm{dL}$ foi de $4,5 \%$ e para uma amostra com valor médio de $496 \mathrm{ng} / \mathrm{dL}$ foi de $3,8 \%(\mathrm{n}=18)$. Já o coeficiente de variação interensaio para as mesmas amostras foi de $4,7 \%$ e $4,8 \%$, respectivamente $(\mathrm{n}=20)$.

\section{Imunoensaio}

Foi utilizado estojo comercial da Roche (Roche Diagnostics, Mannheim, Alemanha) aplicável à plataforma automatizada Modular E170 que emprega anticorpo antitestosterona biotinilado e um derivado de testosterona marcado com complexo de rutênio. A separação é efetuada empregando micropartículas recobertas com estreptavidina, que são capturadas por ação magnética e submetidas à lavagem. A leitura é então efetuada por aplicação de voltagem que induz a emissão de luz pelo complexo de rutênio (ensaio eletroquimioluminescente [ECLIA]). O anticorpo empregado apresenta reatividade cruzada superior a $1 \%$ apenas com 11 -cetotestosterona $(10,4 \%), 11$ - $\beta$-hidroxitestosterona $(8,34 \%)$ e dihidrotestosterona $(1,9 \%)$. A sensibilidade do ensaio é da ordem de $9 \mathrm{ng} / \mathrm{dL}(0,31 \mathrm{nmol} / \mathrm{L})$. O coeficiente de variação intra-ensaio estudado em uma amostra com valor médio de $72 \mathrm{ng} / \mathrm{dL}$ foi de $3,9 \%$ e 
para uma amostra com valor médio de $366 \mathrm{ng} / \mathrm{dL}$ foi de $2,9 \%(\mathrm{n}=20)$. Já o coeficiente de variação interensaio para as mesmas amostras foi de $7,2 \%$ e $4,0 \%$, respectivamente $(\mathrm{n}=20)$.

\section{Fração livre}

A fração livre foi calculada tendo como base a dosagem de testosterona total obtida com os dois métodos mencionados anteriormente, e a dosagem da proteína carregadora de esteróides sexuais (sex hormone-binding globulin [SHBG]) medida por ensaio imunofluorométrico (PerkinElmer). O cálculo segue a fórmula proposta por Vermeulen, Verdouk e Kaufman (9) (www.issam. ch/freetesto.htm).

\section{Métodos estatísticos}

Foi empregado o teste de Wilcoxon para a comparação entre as dosagens pareadas, a correlação de Spearman e o teste para comparação entre dois métodos, descrito por Bland e Altman (14).

\section{RESULTADOS}

Os dados obtidos nas dosagens de testosterona total nas 213 amostras estudadas estão representados na Figura 1A.
A correlação obtida foi de $\mathrm{r}=0,819(\mathrm{p}<0,0001)$, e a mediana das dosagens utilizando o método de rotina (ECLIA) de $27 \mathrm{ng} / \mathrm{dL}(0,94 \mathrm{nmol} / \mathrm{L})$ com intervalo de 9 a $961 \mathrm{ng} / \mathrm{dL}(0,31$ a 33,3 nmol/L); com o ensaio por HPLC/MS-MS, os valores obtidos foram $21 \mathrm{ng} /$ $\mathrm{dL}(0,73 \mathrm{nmol} / \mathrm{L})$ e 7 a $795 \mathrm{ng} / \mathrm{dL}(0,24$ a 27,6 nmol/L, respectivamente. O estudo estatístico empregando o teste de Wilcoxon para amostras pareadas mostrou diferença significativa entre os dados $(\mathrm{p}<0,001)$, e os resultados obtidos por HPLC/MS-MS significativamente mais baixos $(\mathrm{p}<0,0001)$. Os dados correspondentes às determinações de testosterona livre nas 135 amostras estão representados na Figura 1B, e a correlação $\mathrm{r}=0,855(\mathrm{p}<0,0001)$ com medianas de 7,8 (ECLIA) e 7,1 (HPLC/MS-MS) pmol/L, e intervalo de distribuição de 0,8 a 451 e 1,4 a 442 pmol/L, respectivamente. A diferença entre as determinações pareadas mostrou-se também estatisticamente significativa ( $\mathrm{p}=0,0001$, Wilcoxon). A comparação entre os métodos empregando o gráfico de Bland-Altman está representada na Figura 2, sendo o gráfico A correspondente às dosagens de testosterona total $\mathrm{e} O \mathrm{~B}$ às determinações de testosterona livre. Em ordenadas, está representada a relação entre as duas dosagens (ECLIA/HPLC/MS$\mathrm{MS}$ ) e no eixo $\mathrm{X}$ o valor médio obtido para cada soro (ECLIA + HPLC/MS-MS/2).
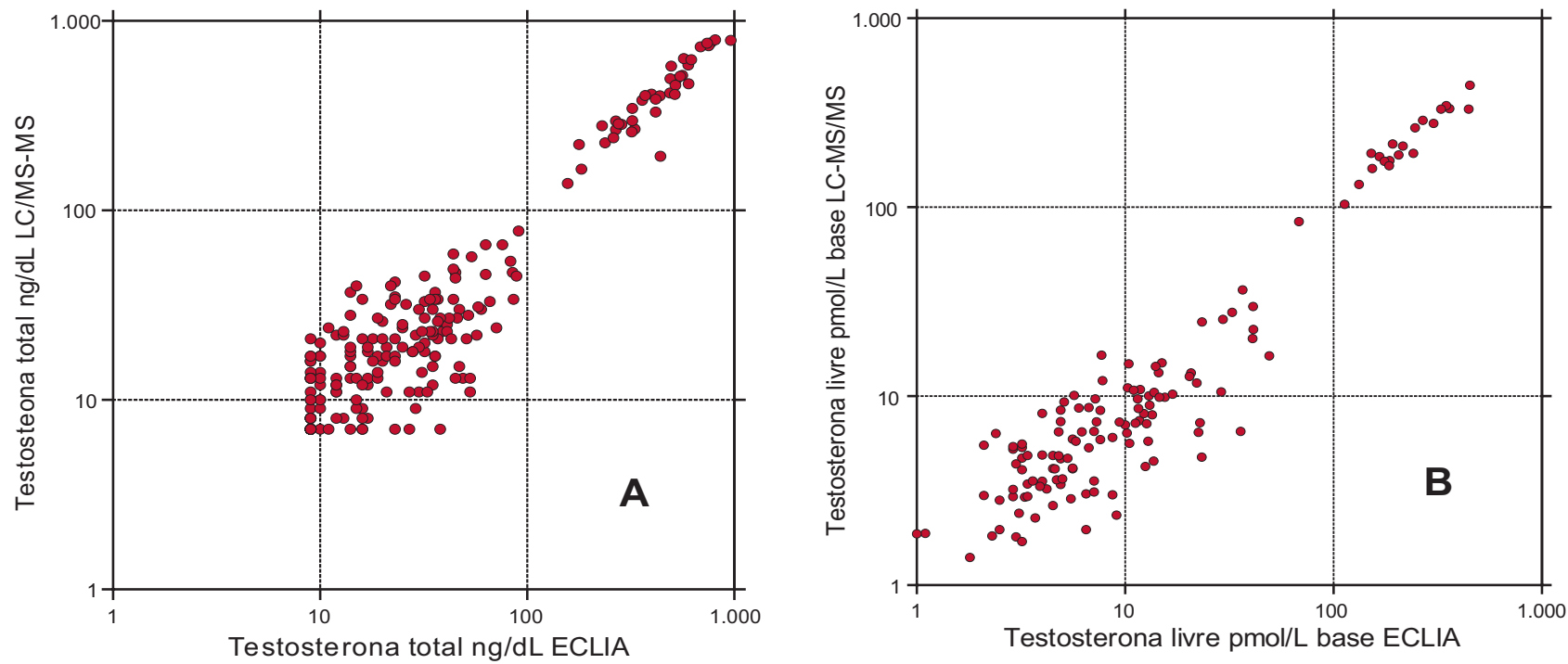

Figura 1. Estudo da correlação entre dosagens de testosterona total realizadas em 213 amostras de soro empregando método automatizado de rotina (ECLIA) e método de HPLC/MS-MS (A) e entre os valores calculados de testosterona livre tendo como base os dois métodos e a dosagem de SHBG (B). 


\section{DISCUSSÃO}

A evolução metodológica propiciou ampla disseminação da dosagem de testosterona, mas ao custo de nítida perda de qualidade. Os estudos comparativos entre diferentes metodologias de rotina e métodos de referência, com preparação por HPLC ou cromatografia a gás, e a leitura por MS-MS mostram nitidamente que, apesar de haver concordância genérica e altos índices de correlação, diferenças importantes são observadas em muitas amostras $(15,16)$. Tais diferenças são mais nítidas em baixas concentrações, como as encontradas em mulheres e crianças.

Os dados obtidos, empregando ensaio de rotina automatizada e comparando-o com o método de referência desenvolvido no HPLC/MS-MS, corrobora os dados da literatura para a dosagem de testosterona total. Fica também evidente a dependência dos métodos com base em cálculo para determinação de testosterona livre na acurácia da determinação de testosterona total. A obtenção de valores mais elevados com o método automatizado era o esperado em razão da presença de potenciais interferentes, cuja importância tende a decrescer na medida em que os valores de testosterona total ficam mais elevados. O exame detalhado dos dois gráficos da Figura 1 mostra claramente a maior dispersão observada nas concentrações mais baixas, conforme relatado na literatura (17). A visualização deste fenômeno é mais clara com o emprego do gráfico de Bland-

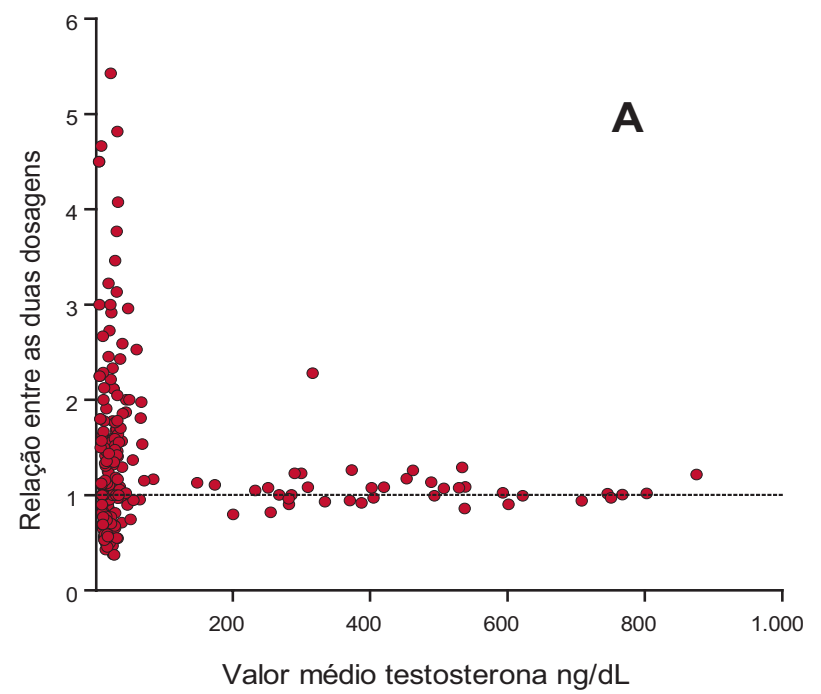

Altman (Figuras 2A e 2B), que compara as médias entre as duas dosagens e a relação entre elas, com a dispersão maior entre os valores mais baixos e o predomínio de valores mais elevados com o ECLIA. O encontro de algumas amostras com valores mais baixos no ECLIA do que com HPLC/MS-MS muito provavelmente se deve à menor acurácia do primeiro.

Em especial para baixas concentrações, é inescapável a conclusão de que as dosagens de testosterona por métodos diretos e automatizados são inaceitáveis. Já é conhecido o fenômeno de presença de interferentes em dosagens de esteróides hormonais, obtidas por métodos sem processos preparativos, tendo sido demonstrada também para a determinação de progesterona e estradiol (18). Por outro lado, a implantação de métodos com processos preparativos por HPLC e medida por espectrometria de massa em tandem implica investimentos em pessoal especializado, instalações e equipamentos, incompatíveis com a remuneração de mercado obtida por laboratórios de rotina para a dosagem de testosterona total ou livre. A evolução das metodologias de referência, tornando-as compatíveis com a realidade de mercado deverá ocorrer, mas ao longo de um tempo razoável. O que fazer neste ínterim? Os dados deste estudo e os da literatura mostram que a valorização de dosagens de testosterona em mulheres e crianças deve ser feita com muito cuidado. A confirmação de valores anormais deve ser realizada com o emprego de metodologias de referência, quando disponíveis. Onde estas não forem disponíveis,

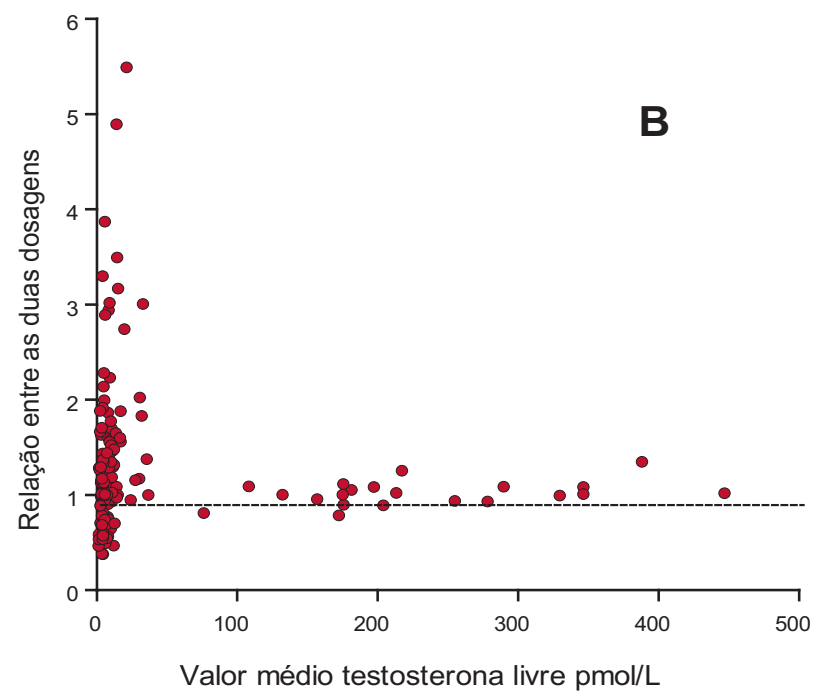

Figura 2. Gráfico de Bland-Altman representando a relação entre as duas dosagens de testosterona total (ECLIA/HPLC/MSMS) e suas respectivas médias (A) e a mesma relação entre a testosterona livre calculada com os dois métodos e respectivas médias (B) em 135 amostras de soro. 
conclusões diagnósticas só devem ser assumidas após comprovação por outros métodos (por exemplo, imagem). Além disso, cuidados simples, como a coleta das amostras em mulheres na fase folicular e a repetição em nova amostra de exames que apresentaram resultados anormais, são medidas básicas para a convivência com as limitações metodológicas aqui apresentadas e discutidas (6).

Conflito de interesse: Os autores declaram não haver potencial conflito de interesse científico.

\section{REFERÊNCIAS}

1. Furuyama S, Mayes DM, Nugent CA. A radioimmunoassay for plasma testosterone. Steroids. 1970;16:415-28.

2. Vieira JGH, Nishida SK, Lombardi MT, Noguti KO. Estudo de um radioimunoensaio para a dosagem de testosterona sérica empregando anticorpo monoclonal. J Bras Patol. 1996;32: 56-63.

3. Shrivastav TG, Basu A, Kariya KP. One step enzyme linked immunosorbent assay for direct estimation of serum testosterone. J Immunoassay Immunochem. 2003;24:205-17.

4. Herold DA, Fitgerald RL. Immunoassays for testosterone in women: better than a guess? Clin Chem. 2003;49:1250-1.

5. Vieira JGH, Ferrer CM, Ghiringhello MT, Nakamura O, Hauache OM. Níveis de testosterona sérica elevados em mulheres: necessidade de confirmação com diferentes metodologias. Arq Bras Endocrinol Metab. 2004;48:429-30.

6. Rosner W, Auchus RJ, Azziz R, Sluss PM, Raff H. Position statement: utility, limitations, and pitfalls in measuring testosterone: an Endocrine Society position statement. J Clin Endocrinol Metab. 2007;92:405-13.

7. Sinha-Hikim I, Arver S, Beall G, Shen R, Guerrero M, Sattler F, et al. The use of a sensitive equilibrium dialysis method for the measurement of free testosterone levels in healthy, cycling women and in human deficiency virus-infected women. $\mathrm{J}$ Clin Endocrinol Metab. 1998;83:1312-8.

8. Rosner W. An extraordinarily inaccurate assay for free testosterone is still with us. J Clin Endocrinol Metab. 2001;86:2903.

9. Vermeulen A, Verdouk L, Kaufman JM. A critical evaluation of simple methods for the stimation of free testosterona. J Clin Endocrinol Metab. 1999;84:3666-72.
10. Vieira JGH, Nakamura OH, Carvalho VM. Dosagem de cortisol e cortisona livres urinários empregando cromatografia líquida associada a espectrometria de massa em tandem (LC-MS/ MS). Arq Bras Endocrinol Metab. 2005;49:291-8.

11. Wang C, Catlin DH, Demers LM, Starcevic B, Swerdloff RS. Measurement of total serum testosterone in adult men: comparison of current laboratory methods versus liquid chromatography-tadem mass spectrometry. J Clin Endocrinol Metab. 2004;89:534-43.

12. Cawood ML, Field HP, Ford CG, Gillingwater S, Kicman A, Cowan $\mathrm{D}$, et al. Testosterone measurement by isotope-dilution liquid chromatography-tandem mass spectrometry: validation of a method for routine clinical practice. Clin Chem. 2005;51:1472-9.

13. Kushnir MM, Rockwood AL, Roberts WL, Pattison EG, Bunker $A M$, Fitzgerald RL, et al. Performance characteristics of a novel tandem mass spectrometry assay for serum testosterone. Clin Chem. 2006;52:120-8.

14. Bland JM, Altman DG. Statistical method for assessment of agreement between two methods of clinical measurement. Lancet. 1986;1:307-10.

15. Dorgan JF, Fears TR, McMahon RP, Friedman LA, Patterson $\mathrm{BH}$, Greenhut SF. Measurement of steroid sex hormones in serum: a comparison of radioimmunoassay and mass spectrometry. Steroids. 2002;67:151-8.

16. Taieb J, Mathian B, Millot F, Patricot M-C, Mathieu E, Queyrel N, et al. Testosterone measured by $10 \mathrm{immunoassays}$ and isotopedilution gas chromatography-mass spectrometry in sera from 116 men, women, and children. Clin Chem. 2003;49:1381-95.

17. Matsumoto AM, Bremner WJ. Editorial: serum testosterone assays - accuracy matters. J Clin Endocrinol Metab. 2004;89:520-4.

18. Vieira JGH, Tachibana TT, Noguti KO, Ferrer CM, Maciel RMB. Valores elevados em ensaios diretos para a medida de hormônios esteróides no soro. J Bras Patol. 1999;35:71-4.

Endereço para correspondência:

José Gilberto H. Vieira

Fleury Medicina e Saúde

Av. General Valdomiro de Lima, 508

04344-903 São Paulo, SP

E-mail: jose.vieira@fleury.com.br 